\title{
Using new technologies to deliver cognitive behaviour therapy with children and adolescents
}

\author{
Caroline L. Donovan, Susan H. Spence and Sonja March
}

The rate at which technology is progressing is astounding. It is hard to believe that the first personal computer was developed only 40 years ago. Today we use computers for information, social networking, work, business, recreation, education and shopping. We 'Google' information and 'Facebook' our status. The very first computers were the size of entire rooms and took hours to process information. Now we carry smartphones in our pockets that process information virtually instantaneously and which have infinitely more power and capabilities than the computing founders would have dreamed possible.

Given the way technology has infiltrated our lives, it is no surprise that it is now being used to assist people with mental health issues. There are mental health websites that provide people with information about various psychological problems, and numerous computer-based therapeutic treatments available. Cognitive behaviour therapy (CBT) is particularly amenable to computerisation given its structured nature (Anderson et al., 2004). Although computer-based CBT treatments were initially met with ambivalence and scepticism, the frequency with which they are appearing together with their evidence-base have signalled a shift in delivery methods for psychological treatments.

Today's children and adolescents have been born into this technological era and view computers, smartphones, laptops and computer games as part of the everyday. They navigate easily in this medium and feel comfortable within it. It would seem therefore, that using technology to assist in the psychological treatment of young people has the potential to be particularly beneficial. Intriguingly, it is only relatively recently that it has been used to assist this population in therapy. However, despite its somewhat recent beginnings, there is a burgeoning growth in research into this important area.

This chapter discusses how technology has been used in CBT treatments with young people and the evidence base for it, and makes suggestions for clinicians thinking of using technology in their CBT practice. Finally, to give a flavour for the nature and potential capacity of computer-based CBT, we present a case illustration of how our own online CBT programme for youth anxiety, BRAVE-ONLINE, has assisted a young child with particularly severe anxiety.

\section{Computer-based psychological treatment programmes for young people}

Cognitive behaviour therapy is effective in treating children and adolescents presenting with a range of psychological disorders. So, why is there a need for technology-based

Cognitive Behaviour Therapy for Children and Families, 3rd edn. ed. Philip Graham and Shirley Reynolds. Published by Cambridge University Press. () Cambridge University Press 2013. 
interventions? Despite the demonstrated efficacy of CBT with youth, unfortunately most young people with mental health issues do not receive professional help (Merikangas et al., 2010). There are numerous reasons why young people fail to receive help, including confidentiality concerns, stigma and embarrassment about attending a mental health service, and beliefs around not being understood or taken seriously. Lack of knowledge about the appropriateness of particular services, and structural factors such as financial concerns, lack of accessibility of services, and long waiting lists have also been found to present barriers to those who require psychological assistance (Boyd et al., 2007).

The use of technology can circumvent almost all of these barriers. Computer-based programmes can be accessed by families in the privacy of their own homes without the concern of being 'seen' at mental health clinics. Technology-based communication also has a 'disinhibition effect' where, because of perceived anonymity, people tend to selfdisclose more (Suler, 2004). Thus, young people may perceive greater confidentiality within a computer-based medium and feel more comfortable disclosing personal information. Not only do the vast majority of youth (at least in developed countries) have access to computers and the Internet, but it has been found that young people, particularly adolescents, use the Internet to seek help and find text-based counselling less confronting than talkbased counselling (Nicholas et al., 2004). Furthermore, most technology-based programmes are constantly available, meaning that they are more accessible, more convenient and people do not generally have to wait to receive treatment. They also have the potential to be delivered, and received, at a relatively low cost if adopted on a wide scale. Thus, technology may be well accepted among young people as a way of seeking help for their emotional concerns, and therefore has the potential to assist in filling a void created by barriers to face-to-face treatment.

It is important to note however, that despite the many benefits associated with computer-based therapy, it is by no means the perfect solution to all difficulties associated with access and uptake of treatment. Despite most youth having access to computers and the Internet, those least likely to have such access are also those most likely to be at risk of a range of mental health problems. That said, such disadvantaged youth are even less likely to have access to high quality face-to-face therapy, and therefore computer-based therapy may reach at least some of those disadvantaged youth who may not have access to clinicbased therapy but who may have access to computers through libraries, schools and other community-based facilities.

Under the overarching 'technology' banner, a number of different approaches have assisted with a variety of childhood psychological afflictions. Before reviewing computerbased programmes and technological adjuncts, it is important to note some features on which the various programmes differ. Important differences lie in the mode of delivery of programmes and the level of therapist involvement they require. The main modes of delivery evident in the child literature to date are either Internet-based, CD-ROM-based, or comprise online chat rooms or discussion-boards, with some programmes integrating more than one of these approaches. Internet-based programmes involve the young person logging in to designated websites and completing sessions online. CD-ROM applications involve the provision to clients of a CD-ROM that presents information and programme content. Chat/discussion forums can be either asynchronous or synchronous. Asynchronous forums can be accessed by a therapist or overseer at any time so that messages/comments can be placed or responded to. Synchronous forums are usually 
group-based, and allow several clients to log in at a predetermined time with a therapist present to conduct the session and organise the forum.

Related to differences in delivery mode, is the level of therapist engagement offered as part of the intervention. Involvement by the therapist can range from none (e.g. completely self-help programmes) to minimal (e.g. weekly email contact), to substantial (e.g. therapist being present for the entire chat session). As will be evident from the discussion below, the various treatment programmes developed to date vary greatly in this regard, with positives and negatives associated with more versus less therapist involvement that will be discussed later. It is first important to review some of the computer-based treatments that have been investigated thus far in the child and adolescent field, for the purpose of providing an understanding of the breadth and variety of what is available and possible. In this way, the reader may gain some understanding of the programmes that might best suit their particular practice, not only in terms of the disorder being treated, but also in terms of the mode of delivery and level of therapist involvement. The review of programmes below is wide but not exhaustive. Rather, prominent programmes have been chosen and grouped within the particular disorder they are designed to treat, in order to demonstrate the diversity between programmes in terms of characteristics and approach.

\section{Anxiety}

Within the anxiety domain, there are examples of Internet-based and CD-ROM programmes that differ with respect to level of therapist involvement. Spence and colleagues (March et al., 2009; Spence et al., 2006, 2011) developed an Internet-based CBT programme called BRAVE-ONLINE for children and adolescents with anxiety disorders. The programme comprises ten youth sessions, six parent sessions and two booster sessions conducted 1 and 3 months after treatment. Each family is allocated a therapist who monitors the family's progress through each session and sends a short weekly email providing encouragement, reinforcement and assistance/redirection when necessary. There is a mid-programme telephone call between therapist and parent to develop the exposure hierarchy that is then worked through by the young person. There have now been three randomised controlled trials (RCTs) (March et al., 2009; Spence et al., 2006, 2011) conducted on the BRAVE-ONLINE programme (with two more underway) that have demonstrated its efficacy. The first RCT, conducted with primary school children, compared a waitlist control group with a group receiving the original clinic version of BRAVE and a condition whereby half of the sessions were completed in the clinic and the other half were completed online (Spence et al., 2006). The results suggested that both treatment groups were superior to the waitlist control group in terms of anxiety and were equally efficacious as each other. The second RCT, also conducted with primary school children, compared a fully online version of BRAVE with a waitlist control group (March et al., 2009). The results indicated that the online programme was efficacious in reducing anxiety in these children, with effect sizes being comparable to those found in clinic-based anxiety studies at follow-up. Finally, the third RCT compared an individual clinic-based version of BRAVE for Teenagers with a fully online version and a waitlist control (Spence et al., 2011). Results indicated that both treatment groups were superior to the waitlist control group and, most importantly, were equally efficacious as each other (Spence et al., 2011). Details of the BRAVE programme will be provided below in the case study. 
Using a different approach, Khanna and Kendall (2010) developed a CD-ROM programme, Camp Cope-A-Lot, for children aged 7-13 years with anxiety. It consists of 12 sessions, the first six of which are entirely self-help (unassisted) whilst the remaining six sessions focus on exposure and require the assistance of a therapist. The therapist is guided by a manual and is responsible for monitoring patient symptoms, facilitating the completion of exposure-based tasks, and providing reinforcement and support as required. In a RCT testing the efficacy of the programme, it was shown to be as efficacious as clinicbased, individual CBT, with both the online programme and individual CBT demonstrating significant superiority over an attention comparison condition (Khanna \& Kendall, 2010).

Also using a CD-ROM delivery mode and therapist assistance is Cunningham et al.'s (2009) Cool Teens CD-ROM for adolescent anxiety disorders. The programme comprises eight sessions with no limit to the order or speed with which teenagers can progress and, in the uncontrolled case-series test of the programme, regular telephone contact with a therapist. In that study, four of the five participants completed at least six of the eight modules and two were free from at least one anxiety disorder upon completion. Those same two participants were free of any anxiety disorder diagnosis at follow-up, suggesting some long-term effectiveness. A subsequent RCT comparing the Cool Teens Programme with a waitlist control group, demonstrated significantly greater reductions in anxiety diagnoses and symptoms for the Cool Teens condition compared with the waitlist condition (Wuthrich et al., 2012).

Using a self-help approach with no therapist intervention, Cox et al. (2010) investigated the usefulness of a web-based early information intervention for children aged 7-16 years who had sustained an unintentional injury. The intervention consisted of a parent pamphlet and an information-based, self-help website for children incorporating strategies such as relaxation, coping statements, problem-solving, identification of personal strengths and reflection on the event. There were no directions around how the programme was to be used, with young people able to access and complete whichever modules they wished. Over a 6-month follow-up period, there was a significant difference over time between the intervention group and the no-intervention control group with respect to anxiety. Whilst the intervention children reduced in anxiety over time, the no-intervention children worsened.

It would seem from the above discussion that, for youth anxiety disorders, computerbased programmes employing various delivery modes and levels of therapist involvement are useful. Although an emerging field of research, the findings for computer-based CBT within this area are encouraging.

\section{Depression}

Within the youth depression literature, perhaps the most well-known internet-based programme is MoodGYM (O'Kearney et al., 2009). MoodGYM comprises five sessions and is entirely self-help with no therapist involvement. The programme has been extensively tested with adults, and has also now been evaluated with adolescents. MoodGYM has been shown to be effective in reducing adolescent depressive symptoms compared with a waitlist control group (Calear et al., 2009), a standard personal development class condition (O'Kearney et al., 2006), and a usual curriculum condition (O'Kearney et al., 
2009). In a study comparing MoodGYM alone, face-to-face therapy alone, face-to-face therapy + MoodGYM and a control group, Sethi et al. (2010) found that MoodGYM was not as effective as face-to-face CBT in reducing depressive symptoms or negative automatic thoughts. It was also found that face-to-face therapy + MoodGYM was better than MoodGYM alone in reducing anxiety, depression, distress and frequency of negative automatic thoughts. Furthermore, face-to-face therapy + MoodGYM was more effective in reducing anxiety and frequency of negative automatic thoughts compared with face-toface therapy. It seems that combining face-to-face therapy and computerised therapy might be particularly useful when targeting anxiety and negative automatic thoughts in young people.

Van Voorhees et al. (2005, 2008, 2009) developed an Internet-based, self-help programme for adolescent depression. The CATCH-IT programme involves 14 Internet-based sessions using strategies derived from CBT, interpersonal psychotherapy and behavioural activation as well as community resiliency concepts. Aimed at youth aged 14-21 years, CATCH-IT was designed for use within a primary care situation whereby a physician initiates use of the programme (Van Voorhees et al., 2005, 2008, 2009). A small initial uncontrolled pilot test of the programme suggested favourable trends (but not statistically significant results) in the reduction of depressive symptoms following treatment. A subsequent study comparing brief physician advice plus the Internet programme with a condition involving motivational interviewing plus the Internet programme suggested that both conditions were equally successful in reducing depressive symptoms, but that the condition involving motivational interviewing demonstrated a significantly greater reduction in hopelessness and suicidal ideation (Van Voorhees et al., 2009).

CD-ROM and discussion forum delivery modes have also been investigated with respect to the computer-based treatment of adolescent depression. Stressbusters (Abeles et al., 2009), for example, is a self-help, CD-ROM programme comprising eight CBT sessions for children aged 12-16 years. In an uncontrolled case series of 23 participants, it was found that the percentage of young people who met diagnostic criteria for depression was reduced after programme completion. Similarly, in an uncontrolled study using a discussion-based therapeutic approach, Gerrits et al. (2007) found that 'Master Your Mood Online' was effective in reducing depressive symptoms. The programme involved eight 1.5-hour chat sessions whereby small groups of teenagers logged in to the chat room at a particular time each week. The sessions were led by a mental health professional who also sent text messages and emails regarding homework tasks.

The variety of approaches used in the computer-based treatment of adolescent depression points to the creativity and potential for technology in this important area. Depression is a highly prevalent disorder associated with a vast array of deleterious consequences. What appears to be lacking in the area of computer-based depression treatment, is the inclusion of studies investigating the efficacy of therapist-mediated programmes. Given the seriousness and prevalence of youth depression, there would seem to be a further need for research in this area to determine whether providing therapist mediation might improve treatment response even more.

The potential for computer-based therapy to reach this group of young people is particularly exciting, and it is hoped that researchers will continue to work towards increasing uptake of, and compliance with, these programmes. 


\section{Substance use}

Within the substance-use domain, a number of innovative programmes have been developed. Schinke and colleagues have produced various self-help programmes, most of which can be used in CD-ROM or Internet forms, for different substance-use issues in adolescents. Although not CBT-based, the programmes are presented here as examples of how technology has been used to treat young people. The programmes are based on family interaction theory and target the relationship between adolescent girls and their mothers. They vary in terms of content, substance focus and the target population. For example, Schinke et al. (2011) investigated the usefulness of a ten-session programme completed at the rate of one session per week, that was aimed at preventing substance use amongst black and Hispanic adolescent girls. The results of the RCT suggested that in comparison to girls in the no-intervention control condition, girls receiving the programme were less depressed, reported higher self-efficacy in their ability to refuse cigarettes, alcohol and drugs, reported lower alcohol use, and reported lower expectations that they would use tobacco, alcohol or prescription drugs. Similarly impressive findings by this research team have been found through a series of RCTs comparing the treatment programme with nointervention control groups. The programmes tested have been found to prevent substance use among girls aged 10-14 years (Fang et al., 2010), prevent alcohol use among late adolescent urban youth (Schwinn \& Schinke, 2010), reduce underage drinking among adolescent girls (Schinke et al., 2009a) and prevent substance use among 11-13-year-old girls (Schinke et al., 2009b).

Schwinn et al. (2010) have also produced the RealTeen programme, an Internet-based, 12 -session programme incorporating general personal and social skills, drug-use information and drug-refusal skills amongst adolescent girls. This innovative self-help programme incorporates blogs, pen pals and a private diary, in addition to the programme. Although an RCT demonstrated no significant differences between the intervention and nointervention group at post-treatment with respect to drug use, at 6-month follow-up girls in the treatment group reported less 30-day marijuana use, poly drug use and total substance use, compared with the no-intervention control group. Finally, Williams et al. (2005) trialled LifeSkills Training, a self-help, CD-ROM programme comprising ten sessions aimed at preventing drug use in 12-13-year-olds by teaching social skills, personal self-management and drug-resistance skills. The results of the RCT suggested that compared with the waitlist control group, teenagers in the treatment group reported lower prodrug attitudes, better normative expectations for peer and adult substance use and better anxiety reduction skills.

Interestingly, all of the computerised therapy programmes in the substance-use area reviewed above are self-help. Yet, despite the lack of therapist monitoring and assistance, they have produced positive results. Self-help programmes have the potential for wide distribution and cost-effectiveness. Given the serious implications of substance use, these prevention and early intervention programmes are particularly exciting and offer great promise as a means by which to reach youth and intercept the potentially devastating trajectories associated with substance use.

\section{Pain}

Within the pain area, Internet-based and CD-ROM-based delivery modes have been used, with varying levels and types of therapist support. Palermo et al. (2009) developed 
a nine-session, Internet-based CBT programme called Web-MAP: Web-based Management of Adolescent Pain for 11-17-year-olds suffering with headache, abdominal pain and/or musculoskeletal pain. The programme comprises nine youth and parent sessions with an online therapist reviewing homework, encouraging practice and assisting with overcoming barriers to therapy. In the RCT conducted, it was found that compared with the waitlist control group, youth in the treatment group showed a greater reduction in activity limitations and pain intensity at post-treatment, a finding which was maintained at 3-month follow-up. Furthermore, the pain of young people in the treatment group improved at a faster rate than that of children in the waitlist control group.

Similar results were found by Connelly et al. (2006) who developed Headstrong, a foursession, CBT-based CD-ROM programme for children aged 7-12 years with headache where therapist assistance was provided via a weekly telephone call. Results of the small RCT suggested that children in the treatment programme demonstrated a significantly greater reduction in pain compared with those in the waitlist group at follow-up. Equally efficacious results have been found by Hicks et al. (2006) using an Internet-based CBT approach for recurrent abdominal pain and/or headache in 6-16-year-olds. The programme comprises an online manual with seven chapters for young people and two chapters for parents. A relaxation tape and thought journal are provided, and young people are assigned skills each week that are discussed in an email or telephone call with a therapist. Results of the small RCT suggested that there was greater clinically significant improvement in the treatment group compared with the standard medical care control group at follow-up.

The programmes reviewed above in the pain area are therapist assisted and have been shown to be effective in reducing various types of pain in young people. Such programmes could potentially be prescribed by general practitioners and hospital staff, who are likely to be the first point of contact for people suffering with pain. It will be interesting to see whether in the future, entirely self-help programmes will be developed in this area, as they would be particularly beneficial in this health-based context.

\section{Eating disorder symptoms and body image problems}

Within the disordered eating/body image realm, a number of innovative and efficacious computer-based programmes have been developed. Heinicke et al. (2007) developed the CBT-based My Body, My Life: Body Image Programme for adolescent girls aged 12-18 years. The programme is discussion-forum based, with the six weekly 90 -minute smallgroup chat room sessions facilitated by a therapist. In the RCT comparing the treatment programme with a waitlist control, it was found that the intervention produced clinically significant changes in body dissatisfaction, disordered eating and depression at postassessment and follow-up (Heinicke et al., 2007).

Using a number of different modes of delivery within the one programme, Jones et al. (2008) developed StudentBodies2BED aimed at reducing binge eating and overweight in adolescents. The 16-session CBT-based programme included psycho-education, interactive components for self-monitoring diet, exercise and thoughts, an asynchronous discussion group and a handbook for parents. Weekly letters focusing on reinforcement, encouragement and motivational messages were also mailed to participants. In a RCT comparing the programme with a waitlist control group, it was found that 
StudentBodies2BED was successful in reducing BMI, binge eating and weight and shape concerns.

Also using a combination of delivery modes, Pretorius et al. (2009) developed and empirically tested their Overcoming Bulimia Online programme. The programme comprises eight 30-40-minute interactive multimedia web-based CBT sessions that are accompanied by a workbook, homework and an 'Anxiety Control Training' audio session. Additionally, a message board provides peer support and participants have an online therapist who provides email support and advice. In an uncontrolled effectiveness study, the authors found significant reductions in eating disorder symptoms and service contacts from pre-treatment to post-treatment that were maintained at 6-month follow-up.

Within the disordered eating/body image area in particular, programme developers have attempted to combine a number of technological delivery modes to produce innovative and engaging programmes for youth. It will be interesting to see, as programmes of this integrative nature are developed and assessed, whether it will be possible to determine which modes of delivery are most useful to youth with particular disorders and/or characteristics.

\section{Comments for clinicians}

From the above discussion, it is evident that there are a number of efficacious computerbased CBT interventions for a variety of youth psychological afflictions. The programmes vary in mode of delivery (Internet, CD-ROM or discussion forum) and level of therapist involvement. Potentially, these programmes can have enormous impact through public health systems, but to do so, they require uptake by government health departments. Internet- and CD-ROM-based programmes require much less (if any) therapist involvement, and, if effective, are time and cost efficient, and more accessible and convenient. There is also the potential to use these programmes in a stepped-care approach. Van der Leeden et al. (2011) has found evidence for the efficacy of a face-to-face stepped-care approach for child anxiety disorders whereby programmes with minimal face-to-face therapist involvement can be implemented as a first step in care that can be followed by more intensive face-to-face therapy if required. Similar opportunities exist for online therapy, whereby an online programme could comprise the first step in care, to be followed by a face-to-face intervention if deemed necessary.

It is likely that computerised therapy programmes will become more available to clinicians as time passes. Although computer-based therapy for youth is in its infancy, it is progressing at an energetic pace and demonstrating efficacy in many areas. There will be obstacles to overcome even when these programmes become available to clinicians. How long will it take for public and private health funds to recognise the benefits of computerbased therapy as an efficacious treatment modality and provide the rebates and payments offered for face-to-face therapy? Will therapists require specialised training to deliver these programmes effectively? If available to private psychologists, how expensive will these programmes be and how will they be made available? These and other challenges must be overcome before computer-based programmes are commonplace.

If and when these programmes become available to clinicians in the public or private sectors, there are a number of characteristics to be considered when deciding on the type of programme that might be most useful. Internet-based programmes have the advantage that data entered in by clients is accessible to the therapist. Through monitoring, a therapist can 
ascertain how well a client is progressing through the programme and completing homework, and can provide e-mail or telephone assistance as required. The speed with which clients can progress through sessions can also be dictated by the therapist, so that clients do not skip sessions or rush through the programme without having time to process the content adequately.

Another consideration for clinician uptake of technology-based programmes is the mode of delivery. That the client must have Internet access is a disadvantage of online delivery, as is the myriad of potential technological problems such as slow Internet speed and server problems that may hinder a client's progress through the programme. Not requiring Internet access, CD-ROM-based programmes have a number of advantages. They may be more accessible to families unable to access the internet, they have potentially fewer technological problems and they allow easier video and audio streaming. One of the downsides of CD-ROM applications is that they still rely on computer access, and it is more difficult for therapists to monitor the client's progress as they rely on clients sending or uploading information to the therapist. Clients may also skip sessions, complete sessions in any order, or rush through the programme, thus rendering the programme potentially less effective than it could be.

Whilst Internet-based and CD-ROM-based computerised therapies are similar in many respects, chat- or discussion-based programmes are quite different. Chat- or discussion forum-based programmes allow for group therapy to occur online and thus have more potential (albeit virtual) for peer-based interaction and support. Although no more time and cost-efficient than group-based face-to-face therapy, they are likely to be much less confronting and much more accessible, particularly for clients in rural and remote areas, or where psychological expertise is sparse. Furthermore, the therapist is potentially able to monitor progress more carefully, accurately and quickly than through either Internet-based or CD-ROM-based applications as the communication occurs in real time. The use of such forums, however, requires careful monitoring and moderating to avoid the risks (e.g. sharing of unmonitored inappropriate personal information and message content that may be inappropriate, offensive or unsolicited) inherent in such media.

There is also the potential to use a mixed mode of delivery for therapeutic programmes. For example, clinic visits could be supplemented with online therapy, and online therapy could take many forms. Video-clips demonstrating certain skills could be incorporated into online programmes, and chat rooms, Facebook groups and YouTube could potentially be used as vehicles to deliver therapy. Video-conferencing could also be used to bring young people together for group-based therapy aimed at a number of childhood disorders. Virtual Reality therapy is another area of enormous potential. The creation of virtual environments has allowed the production of simulations to target a variety of anxiety disorders such as specific phobia, social phobia, panic disorder and agoraphobia (Wiederhold \& Wiederhold, 2005).

Two other issues require mention. First, as with face-to-face therapy, confidentiality is of utmost importance. Online therapists must ensure that appropriate firewalls, passwords and safe electronic storage of client data are maintained at all times. Second, compliance and rate of progression through computer-based therapy are also important issues as both tend to be lower than face-to-face therapy (March et al., 2009). These problems are most relevant to Internet-based and CD-ROM-based programmes where completion and progression through sessions is often at the discretion of the young person. Without a set appointment time, motivation and self-discipline is required to ensure that sessions are 
completed on schedule. This difficulty can be compounded for programmes that have no therapist involvement, as completion and progress are not monitored or encouraged. A potentially useful inclusion to computer-based programmes may be the use of incentives for therapy compliance. Although not, to our knowledge, tested with clinical samples, Fridrici and Lohaus (2009) investigated the usefulness of incentives with eighth graders participating in an Internet-based stress-prevention programme. Those who were told they were in the draw for a raffle were more likely to be retained, reported higher acceptance rates and reported greater programme effectiveness. Although the use of incentives clearly requires more research, this study provides preliminary support for their potential usefulness.

In summary, there are positives and negatives associated with each mode of computerbased programme delivery. Clinicians need to assess the characteristics of particular programmes to determine the fit between their clinical practice requirements and what the particular programmes offer. Clinicians do seem to be embracing the idea of computerbased therapy. Clinicians have been found to be cautious but positive about computerbased therapy with young people, thinking it best for preventive purposes and for low- to moderate-severity psychological issues, and being less positive about programmes that do not require any therapist assistance (Stallard et al., 2010). Given that more computer-based programmes and evidence for these programmes are likely to emerge, the generally positive view by clinicians may ensure better uptake.

\section{Technological adjuncts for CBT programmes}

The discussion above has centred on CBT treatment programmes delivered entirely through technological media. However, there are many and varied ways technology has been used to augment clinic-based treatment. Some authors have developed computer games or program to increase therapeutic engagement. For example, quite early on, Clarke and Schoech (1995) used a computer game similar to Dungeons and Dragons Adventure where there were a series of levels and rooms, the completion of which required problemsolving skills, impulse control techniques and other behavioural strategies. The purpose of the game was to engage teenagers in therapy, to discuss the therapeutic techniques learned during face-to-face therapy. The authors provided a brief descriptive report on its use with four teenagers who were said to respond positively to the inclusion of the game.

Informational websites and CD-ROMs are another way technology can be used to assist in therapy. These technologies have been used in many areas within health psychology for young people, such as for those who smoke (Mermelstein \& Turner, 2006), have cystic fibrosis (Davis et al., 2004), leukaemia (Dragone et al., 2002) or chronic constipation (Ritterband et al., 2005). The information provided is up-to-date, interesting and interactive and maximises the attention and interest of young people.

Chat rooms and discussion forums that are not designed to deliver therapy per se, but exist for support and self-expression, have also been developed. Although not specifically tested as an adjunct to therapy, they certainly have the potential to be so. For instance, support-based discussion forums have been developed for children coping with parental cancer (Giesbers et al., 2010) and young people with depression (DeMaso et al., 2006). Compared with face-to-face support groups, such online support groups are more accessible and perhaps more attractive to young people. They may also provide a useful addition to the help received from the young person's therapist. 
Technology has also been used as a direct therapeutic adjunct to teach particular skills within a face-to-face therapy context. For example, in a very creative study, Beaumont and Sofronoff (2008) developed The Junior Detective Training Programme for children with Asperger syndrome. The programme includes clinic-based group social skills training, parent training, teacher handouts and a computer game which assists children to develop emotion recognition, emotion regulation and social skills. Set in 2030, the main character is a secret agent who specialises in 'controlled remote viewing' (or the decoding of thoughts and feelings). Results of the RCT suggested that children receiving the treatment programme demonstrated greater improvement in social skills and emotional understanding compared with those in the waitlist group (Beaumont \& Sofronoff, 2008), demonstrating the usefulness of augmenting an essentially clinic-based programme with technology to heighten child engagement and assist in skills teaching.

Also in the autistic spectrum area, Silver and Oakes (2001) conducted ten half-hour computer-based sessions over 2 weeks with 12-18-year-olds with autism or Asperger syndrome. The computer-based programme focused on emotional recognition and prediction, and was shown in the small RCT to be effective in improving these skills compared with a no-intervention control group. Although designed to be only a component of therapy, the programme illustrates the usefulness of this medium in a population often found to engage particularly well with it.

Yet another technological adjunct that we are likely to see incorporated into therapy more, is the mobile phone. Mobile smartphones have been investigated as a potential tool in therapy with young people, particularly with respect to the monitoring of mood and/or behaviour. For instance, Shapiro et al. (2010) used text messaging in their 12-session group CBT programme for adolescent bulimia nervosa. Participants were required to send a nightly text message to their therapist about the number of binge eating and purging episodes they had engaged in, as well as ratings of their urges to binge and purge. The participants received an automatic return text message with feedback. The uncontrolled study suggested that the programme produced significant benefits, and the use of mobile monitoring was well received by participants.

Other studies have also investigated the use of mood and behaviour monitoring using mobile phones with non-clinical samples. For instance, Matthews et al. (2008) investigated the usefulness of mobile phones in monitoring adolescent mood and found that compliance with therapy tasks was much higher amongst youth using mobile phones rather than traditional paper and pencil to chart their mood. In a study conducted to assess whether text messages might assist in encouraging youth to engage in more physical activity, Sirriyeh et al. (2010) showed that for young people who were initially inactive, the use of text messages targeting affective beliefs (e.g. exercise makes you feel happy) increased their activity levels significantly more than instrumental messages (e.g. exercise can assist you to maintain a healthy weight) or when both messages were combined. Continued research investigating the usefulness of text messages in therapy and specific message content is clearly required. Mobile phones have the potential to be very useful as adjuncts to therapy given their popularity amongst youth.

\section{Comments for clinicians}

The above discussion highlights the ways in which technology has the potential to augment face-to-face therapy. Whether it be to engage youth in therapy, teach them specific skills, 
provide information or monitor thoughts, feelings and/or behaviour, the use of technology may well be beneficial. Unlike the fully computerised psychological programmes that have been developed, the potential for mental health professionals to use technology as an adjunct to therapy to engage, inform and assist youth, is immediate and endless. Software will become more available for monitoring via mobile phones and email can be used by virtually any clinician. Young people born into the technological era are particularly likely to embrace and enjoy these adjuncts, and clinicians should keep abreast of the exciting opportunities to deliver CBT creatively.

\section{Case illustration of BRAVE-ONLINE}

As an example of the potential efficacy of a computer-based therapeutic approach, we present Emily, a 4-year-old girl with severe anxiety who was treated using the BRAVEONLINE programme. BRAVE is an Internet-based CBT programme for anxiety disorders in children and adolescents that has demonstrated efficacy with both populations. The programme has been described in detail elsewhere (Spence et al., 2008) and so only a brief overview is given here. BRAVE comprises ten core child and six core parent sessions, with a version for children aged 7-12 years and a version for adolescents aged 13-17 years. Child and parent responses are recorded in the back end of the programme and are accessible to the online therapist. The therapist reviews the family's responses each week and sends a short email providing encouragement, reinforcement and assistance where required. There is also a mid-programme telephone call between the therapist and parent to assist in construction of the BRAVE Ladder (exposure hierarchy).

BRAVE is an acronym for the CBT strategies delivered in the programme. B stands for Body Signs, and refers to the detection of physiological reactions to anxiety. R stands for Relax where different relaxation strategies are taught and a relaxation $\mathrm{CD}$ is provided to the young person. A stands for Activate Helpful Thoughts and comprises the skills of thought detection, cognitive restructuring and coping statements. V stands for Victory Over Your Fears and incorporates both graded exposure and problem-solving. Finally, E stands for Enjoy! Reward Yourself and refers to self and parent reinforcement of full and partial success of brave rather than anxious behaviours.

Case illustrations of BRAVE-ONLINE involving primary school children and secondary school adolescents have been provided in Spence et al. (2008) and demonstrate the success of online therapy with such age groups. However, because preschool children can also have clinical level anxiety disorders, it has been of recent interest to us to determine whether BRAVE-ONLINE can also be used to alleviate anxiety in younger children. Given that 4year-olds are not able to work online by themselves, this case reports the use of BRAVEONLINE parent sessions which were accompanied by a booklet containing age-appropriate examples and details for each session. Previously, the parent programme had only been used in conjunction with the child programme for older children. We had not yet tested the usefulness of the parent-only version of BRAVE-ONLINE for any age group, and the parent programme was initially designed with older children in mind. However, the content of the parent sessions is also highly applicable to younger children. Table 23.1 provides an overview of the parent sessions and Figure 23.1 shows a screenshot from the programme. At the time of publication, the results of the randomised controlled trial for younger children are pending. However, we present here a case study of a young girl with selective mutism to illustrate the usefulness of a parent-only version of BRAVE-ONLINE. 
Table 23.1 Session-by-session overview of BRAVE-ONLINE parent programme.

Session $1 \quad$ What is anxiety?

Why children develop anxiety problems and learning influences

Session 2 Managing your child's anxiety

Parent coping strategies

Ignoring fearful behaviours

Praising BRAVE behaviours

Session 3 Anxious body signs and relaxation

Session 4 Activate helpful thoughts

Understanding thoughts and feelings

Being a thought detective

Session $5 \quad$ Victory over fears

Understanding avoidance

Having victory over fears

Exposure using the BRAVE ladder

Rewards

Session 6 Problem solving and planning for the future

Booster 1 Programme review

Choosing BRAVE strategies, relaxation

Booster 2 Being BRAVE, problem-solving, rewards, BRAVE plans

BRave for PaRents

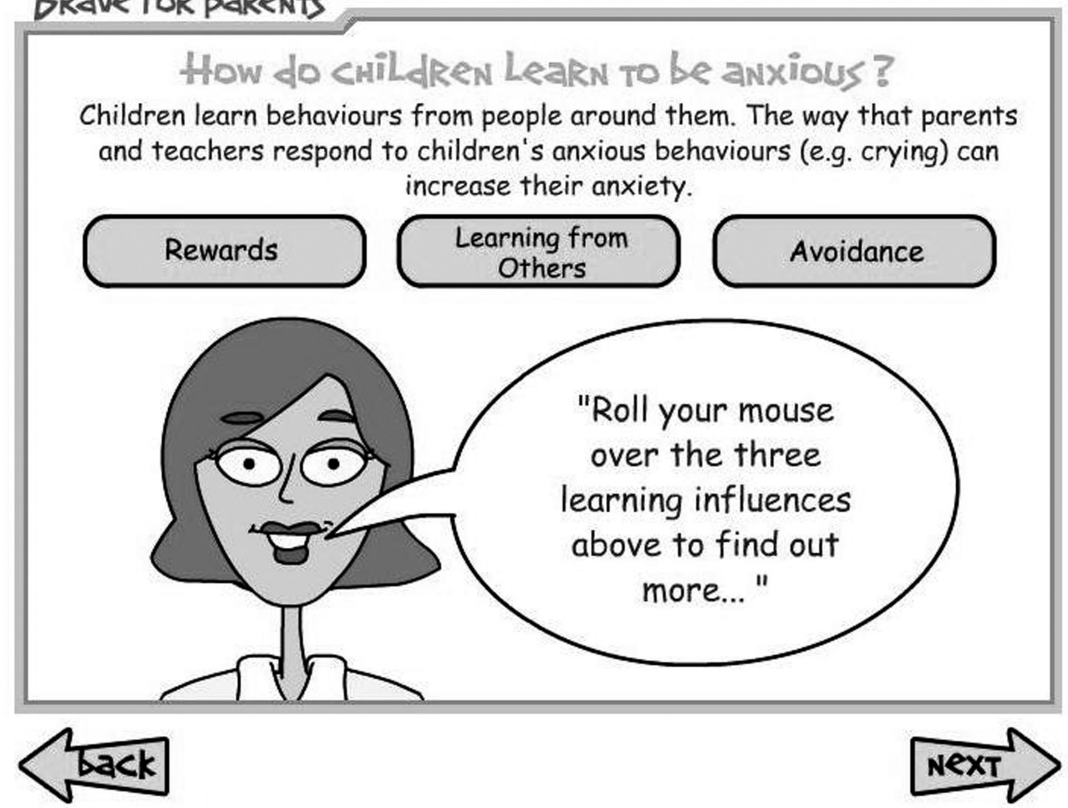

Figure 23.1 Screenshot from the BRAVE-ONLINE parent programme. 


\section{Presenting problem}

Emily's mother contacted the BRAVE team with concerns about her child's anxiety. Emily lived with both biological parents (Mary, 38 years and John, 46 years) and two older siblings. Although talkative at home, Mary reported that Emily rarely spoke outside the home, refused to speak to others who might try to engage her in conversation, and had only one friend. Mary reported that Emily would not ask questions or for help at her preschool playgroup, and would not be involved with show-and-tell. She also refused to play in a group, be involved in sport, talk on the phone or speak to non-family members. Additionally, Mary suggested that Emily had some separation concerns as Emily was tearful upon separation every day at playgroup, and was never left with friends or relatives due to the extreme anxiety reaction it provoked. Mary also reported having to stay with Emily in order for her to sleep, needing to get in the pool with Emily at swimming lessons, and assisting in all lessons at gymnastics so that Emily would participate.

\section{Assessment}

Table 23.2 provides a summary of Emily's scores on each measure at pre-treatment, posttreatment and 6-month follow-up. Emily's diagnostic status was assessed using the Anxiety Disorders Interview Schedule - Parent version (ADIS-P) (Silverman \& Nelles, 1988). Administered over the telephone, each diagnosis was given a clinical severity rating (CSR) from 0 (absent) to 8 (very disabling or disturbing) by the administering clinician, where a CSR of 4 and above suggested a clinical level of anxiety disorder. From the ADIS-P it was evident that, prior to treatment, Emily met DSM-IV diagnostic criteria for selective mutism $(\operatorname{CSR}=8)$, social phobia $(\operatorname{CSR}=8)$ and separation anxiety $(\operatorname{CSR}=4)$.

Following the ADIS-P interview, the clinician ranked Emily's level of functioning using the Children's Global Assessment Scale (CGAS) (Shaffer et al., 1983). The CGAS provides a measure of overall functioning on a scale of $0-100$, with higher scores indicative of higher functioning. As is evident from Table 23.1, Emily's CGAS rating was 49, placing her in the moderately disabled range.

Finally, Mary completed the Preschool Anxiety Scale (PAS; Spence \& Rapee, 1999). The PAS is a 28-item scale requiring parents to rate how true each item is for their child on a 5-point scale from 0 (not at all true) to 5 (very often true). A total score on the PAS can be derived from the addition of all 28 scale items, and six subscale scores can be computed assessing generalised anxiety, social anxiety, obsessive-compulsive disorder, physical injury fears and separation anxiety. Consistent with the ADIS-P interview, Emily was found to be in the clinical range for Social Phobia and Separation Anxiety prior to treatment (see Table 23.2).

\section{Progression through therapy}

Mary's therapist was a clinical psychology $\mathrm{PhD}$ student who followed the family's progress through therapy. Mary completed all six core sessions on time and provided very thoughtful and detailed answers to questions throughout the programme. She also completed all homework and she and Emily's father John constructed an excellent hierarchy which required only minor tweaking by the therapist (see Table 23.2). John was also involved in the therapy, providing support for the implementation of the strategies and participating in Emily's rewards, such as a family picnic.

Mary was slower to complete the booster sessions, completing Booster 1 approximately 2 weeks late and Booster 2 approximately 5 months late. Mary reported that Booster 2 was late because the family had been on an extended holiday with no Internet access. 
Table 23.2 Emily's scores on each of the outcome measures.

\begin{tabular}{llll}
\hline & Pre-treatment & Post-treatment & 6-month follow-up \\
\hline CSR & & & \\
Selective mutism & 8 & 0 & 0 \\
Social phobia & 8 & 4 & 0 \\
Separation anxiety & 4 & 0 & 0 \\
CGAS & 49 & 61 & 88 \\
PAS & & & 15 (normal) \\
Total score & 54 (clinical range) & 35 (elevated) & 0 (normal) \\
GAD & 5 (normal) & 1 (normal) & 9 (normal) \\
Social phobia & 21 (clinical) & 20 (clinical) & 0 (normal) \\
OCD & 3 (normal) & 0 (normal) & 3 (normal) \\
Physical injury & 13 (elevated) & 6 (normal) & \\
Fears & 12 (clinical) & 8 (subclinical) & 3 (normal) \\
Separation anxiety & &
\end{tabular}

CSR, clinician severity rating; CGAS, Global Assessment Scale for Children; PAS, Preschool Anxiety Scale; GAD, generalised anxiety disorder; OCD, obsessive-compulsive disorder.

\section{Therapeutic outcome}

As is evident from Table 23.2, Emily's anxiety was reduced following online therapy. At post-treatment, Emily was no longer selectively mute and had lost her separation anxiety diagnosis. The CSR of her social phobia diagnosis had reduced from eight to four by post-treatment. On the PAS, Emily's total score had reduced from the clinical range to the elevated range, and her separation anxiety subscale score had reduced from the clinical to non-clinical range. Her social phobia subscale score however, remained in the clinical range, although her CGAS score had improved from moderately disabling to slightly disabling. By 6-month follow-up, Emily did not meet diagnostic criteria for any anxiety disorder, all PAS scores had dropped to within normal ranges, and her CGAS rating was also in the normal range. Mary reported high levels of satisfaction with the programme, writing the following e-mail to the online therapist at the 6-month followup point:

Thank you so much for the feedback and for selecting us for the programme. It has been a wonderful success for Emily and we are very grateful to you all for that. She has blossomed so much that we almost forget where she started. I looked back over my earlier notes the other day and was shocked when reminded of where Emily used to be. It is so wonderful for us to watch Emily now - she is so confident at Kindergarten she has quite a large following of admirers! We cannot thank you enough.

It should be noted that Mary was the model client. She was motivated, engaged and compliant. Not all participants are responding this well to the programme, and we are by no means attempting to suggest that they are. Furthermore, given the young age of Emily, we cannot be sure that improvements were not due to the passage of time rather than the intervention. This case study is merely provided to illustrate what can be achieved when clients engage well in computerised programmes, even when they are somewhat 
Table 23.3 Emily's exposure hierarchy. User Goal: To look and smile at and respond to all people's/grown-up's questions. Fear rating :10 Reward: A picnic out with the whole family.

\begin{tabular}{|c|c|c|c|}
\hline Step & My steps & $\begin{array}{l}\text { Fear } \\
\text { rating }\end{array}$ & My rewards \\
\hline Step 10 & $\begin{array}{l}\text { Look and smile and respond to several questions } \\
\text { from unfamiliar people. }\end{array}$ & 9 & $\begin{array}{l}\text { A new book or puzzle of } \\
\text { choice }\end{array}$ \\
\hline Step 9 & $\begin{array}{l}\text { Look and smile and respond to several questions } \\
\text { from friends and familiar people i.e. friend's } \\
\text { parents, carers at playgroup etc. }\end{array}$ & 9 & $\begin{array}{l}\text { Go with Mum to the } \\
\text { park for a play }\end{array}$ \\
\hline Step 8 & $\begin{array}{l}\text { Look and smile and respond to one question } \\
\text { from unfamiliar people }\end{array}$ & 8 & $\begin{array}{l}\text { Go with Mum for a } \\
\text { cupcake and a } \\
\text { milkshake }\end{array}$ \\
\hline Step 7 & $\begin{array}{l}\text { Look and smile and respond to one question } \\
\text { from friends and familiar people i.e. friend's } \\
\text { parents, carers at playgroup etc. }\end{array}$ & 8 & Get a small food treat \\
\hline Step 6 & $\begin{array}{l}\text { Look and smile and say 'thank you' when served } \\
\text { in a shop }\end{array}$ & 8 & $\begin{array}{l}\text { Your choice of activity } \\
\text { with mum for } 30\end{array}$ \\
\hline Step 5 & $\begin{array}{l}\text { Look and smile and say 'good thank you' when } \\
\text { asked how you are }\end{array}$ & 7 & $\begin{array}{l}\text { Pushed on the swing for } \\
15 \text { minutes }\end{array}$ \\
\hline Step 4 & $\begin{array}{l}\text { Look and smile and say 'hello' when greeted or } \\
\text { 'goodbye' when farewelled }\end{array}$ & 6 & $\begin{array}{l}\text { Help complete a jigsaw } \\
\text { of choice }\end{array}$ \\
\hline Step 3 & $\begin{array}{l}\text { Look and smile and wave when greeted } \\
\text { or farewelled }\end{array}$ & 5 & Get a small food treat \\
\hline Step 2 & Look and smile at people when spoken to & 4 & Read a story of choice \\
\hline Step 1 & Look at people when spoken to & 2 & Praise and a cuddle \\
\hline
\end{tabular}

rudimentary in nature. Mary and Emily's therapist spent a total of 2 hours with this family, all over the telephone and internet. Thus, for mothers of young children with anxiety disorders who might find it difficult to attend face-to-face therapy, the implications of this treatment modality are great.

\section{Concluding comments}

Our intention for this chapter was to provide the reader with an overview of the ways in which technology has been used and can be used, to treat young people with psychological difficulties. Whether in the form of full CBT programmes delivered over the Internet, via $\mathrm{CD}$-ROM or through chat-rooms, or as an adjunct to face-to-face therapy, the possibilities for using technology in treating young people are virtually endless. It has never been the intention of developers of computer-based programmes to replace the face-to-face therapist. Rather, technology should be viewed by all as an amazing opportunity to reach otherwise untreated young people and to enhance our face-to-face practice. It is our hope that the reader has come away from the chapter excited by the possibilities and 
opportunities that technology can provide to deliver therapy to young people in new, engaging and creative ways.

\section{References}

Abeles, P., Verduyn, C., Robinson, A. et al. (2009). Computerized CBT for adolescent depression ('Stressbusters') and its initial evaluation through an extended case series. Behavioural and Cognitive Psychotherapy, 37, 151-165.

Anderson, P., Jacobs, C. \& Rothbaum, B. O. (2004). Computer-supported cognitive behavioral treatment of anxiety disorders. Journal of Clinical Psychology, 60, 253-267.

Beaumont, R. \& Sofronoff, K. (2008). A multi-component social skills intervention for children with Asperger syndrome: The Junior Detective Training Program. Journal of Child Psychology and Psychiatry, 49, 743-753.

Boyd, C., Francis, K., Aisbett, D. et al. (2007). Australian rural adolescents' experiences of accessing psychological help for a mental health problem. Australian Journal of Rural Health, 15(3), 196-200.

Calear, A. L., Christensen, H., Mackinnon, A. \& Griffiths, K. M. (2009). The YouthMood Project: a cluster randomized controlled trial of an online cognitive behavioral program with adolescents. Journal of Consulting and Clinical Psychology, 77, 1021-1032.

Clarke, B. \& Schoech, D. (1995). A computer-assisted therapeutic game for adolescents. Computers in Human Services, 11, 121-140.

Connelly, M., Rapoff, M. A., Thompson, N. \& Connelly, W. (2006). Headstrong: a pilot study of a CD-ROM intervention for recurrent pediatric headache. Journal of Pediatric Psychology, 31, 737-747.

Cox, C. M., Kenardy, J. A. \& Hendrikz, J. K. (2010). A randomized controlled trial of a web-based early intervention for children and their parents following unintentional injury. Journal of Pediatric Psychology, 35, 581-592.

Cunningham, M., Wuthrich, V., Rapee, R. et al. (2009). The Cool Teens CD-ROM for anxiety disorders in adolescents. European Child and Adolescent Psychiatry, 18(2), 125-129.

Davis, M. A., Quittner, A. L., Stack, C. M. \& Yang, M. C. K. (2004). Controlled evaluation of the STARBRIGHT CD-ROM program for children and adolescents with cystic fibrosis. Journal of Pediatric Psychology, 29(4), 259-267.

DeMaso, D. R., Marcus, N.E., Kinnamon, C. \& Gonzalez-Heydrich, J. (2006). Depression experience journal: a computer-based intervention for families facing childhood depression. Journal of the American Academy of Child and Adolescent Psychiatry, 45, 158-165.

Dragone, M. A., Bush, P. J., Jones, J. K., Bearison, D. J. \& Kamani, S. (2002). Development and evaluation of an interactive CD-ROM for children with leukemia and their families. Patient Education and Counseling, 46(4), 297-307.

Fang, L., Schinke, S. P. \& Cole, K. C. A. (2010). Preventing substance use among early AsianAmerican adolescent girls: initial evaluation of a web-based, mother-daughter program. Journal of Adolescent Health, 47, 529-532.

Fridrici, M. \& Lohaus, A. (2009). Stress-prevention in secondary schools: online- versus face-toface-training. Health Education, 109, 299-313.

Gerrits, R. S., van der Zanden, R., Visscher, R. \& Conijn, B. (2007). Master your mood online: a preventive chat group intervention for adolescents. Australian e-Journal for the Advancement of Mental Health, 6(3). 
Giesbers, J., Verdonck-de Leeuw, I. M., van Zuuren, F. J., Kleverlaan, N. \& van der Linden, M.H. (2010). Coping with parental cancer: web-based peer support in children. Psycho-Oncology, 19, 887-892.

Heinicke, B., Paxton, S., McLean, S. \& Wertheim, E. (2007). Internet-delivered targeted group intervention for body dissatisfaction and disordered eating in adolescent girls: a randomized controlled trial. Journal of Abnormal Child Psychology, 35, 379-391.

Hicks, C. L., von Baeyer, C.L. \& McGrath, P.J. (2006). Online psychological treatment for pediatric recurrent pain: a randomized evaluation. Journal of Pediatric Psychology, 31, 724-736.

Jones, M., Luce, K. H., Osborne, M. I. et al. (2008). Randomized, controlled trial of an internetfacilitated intervention for reducing binge eating and overweight in adolescents. Pediatrics, 121, 453-462.

Khanna, M. S. \& Kendall, P. C. (2010). Computer-assisted cognitive behavioral therapy for child anxiety: results of a randomized clinical trial. Journal of Consulting and Clinical Psychology, 78, 737-745.

March, S., Spence, S. H. \& Donovan, C. L. (2009). The efficacy of an internet-based cognitivebehavioral therapy intervention for child anxiety disorders. Journal of Pediatric Psychology, 34, 474-487.

Matthews, M., Doherty, G., Sharry, J. \& Fitzpatrick, C. (2008). Mobile phone mood charting for adolescents. British Journal of Guidance and Counselling, 36, 113-129.

Merikangas, K. R., He, J.-P., Brody, D. et al. (2010). Prevalence and treatment of mental disorders among US children in the 2001-2004 NHANES. Pediatrics, 125, 75-81.

Mermelstein, R. \& Turner, L. (2006). Web-based support as an adjunct to group-based smoking cessation for adolescents. Nicotine and Tobacco Research, 8(Suppl 1), S69-S76.

Nicholas, J., Oliver, K., Lee, K. \& O'Brien, M. (2004). Help-seeking behaviour and the Internet: an investigation among Australian adolescents. Australian e-Journal for the Advancement of Mental Health, 3(1). Retrieved from http://www.auseinet.com/journal/vol3iss1/index.php

O'Kearney, R., Gibson, M., Christensen, H. \& Griffiths, K. M. (2006). Effects of a cognitivebehavioural internet program on depression, vulnerability to depression and stigma in adolescent males: a school-based controlled trial. Cognitive Behaviour Therapy, 35, 43-54.

O'Kearney, R., Kang, K., Christensen, H. \& Griffiths, K. (2009). A controlled trial of a schoolbased Internet program for reducing depressive symptoms in adolescent girls. Depression and Anxiety, 26, 65-72.

Palermo, T. M., Wilson, A. C., Peters, M., Lewandowski, A. \& Somhegyi, H. (2009). Randomized controlled trial of an Internet-delivered family cognitive-behavioral therapy intervention for children and adolescents with chronic pain. PAIN, 146, 205-213.

Pretorius, N., Arcelus, J., Beecham, J. et al. (2009). Cognitive-behavioural therapy for adolescents with bulimic symptomatology: the acceptability and effectiveness of internet-based delivery. Behaviour Research and Therapy, 47, 729-736.

Ritterband, L. M., Borowitz, S., Cox, D. J. et al. (2005). Using the Internet to provide information prescriptions. Pediatrics, 116, e643-e647.

Schinke, S. P., Cole, K. C. A. \& Fang, L. (2009). Gender-specific intervention to reduce underage drinking among early adolescent girls: a test of a computer-mediated, mother-daughter program. Journal of Studies on Alcohol and Drugs, 70, 70-77.

Schinke, S. P., Fang, L. \& Cole, K. C. (2009). Computer-delivered, parent-involvement intervention to prevent substance use among adolescent girls. Preventive Medicine, 49, 429-435. 
Schinke, S. P., Fang, L., Cole, K. C. \& Cohen-Cutler, S. (2011). Preventing substance use among Black and Hispanic adolescent girls: results from a computer-delivered, mother-daughter intervention approach. Substance Use and Misuse, 46, 35-45.

Schwinn, T. M. \& Schinke, S.P. (2010). Preventing alcohol use among late adolescent urban youth: 6-year results from a computer-based intervention. Journal of Studies on Alcohol and Drugs, 71, 535-538.

Sethi, S., Campbell, A. J. \& Ellis, L. A. (2010). The use of computerized self-help packages to treat adolescent depression and anxiety. Journal of Technology in Human Services, 28(3), $144-160$.

Shaffer, D., Gould, M. S., Brasic, J. et al. (1983). A Children's Global Assessment Scale (CGAS). Archives of General Psychiatry, 40, 1228-1231.

Shapiro, J. R., Bauer, S., Andrews, E. et al. (2010). Mobile therapy: use of text-messaging in the treatment of bulimia nervosa. International Journal of Eating Disorders, 43, 513-519.

Silver, M. \& Oakes, P. (2001). Evaluation of a new computer intervention to teach people with autism or Asperger syndrome to recognize and predict emotions in others. Autism, 5, 299-316.

Silverman, W. K. \& Nelles, W. B. (1988). The Anxiety Disorders Interview Schedule for Children. Journal of the American Academy of Child and Adolescent Psychiatry, 27, 772-778.

Sirriyeh, R., Lawton, R. \& Ward, J. (2010). Physical activity and adolescents: an exploratory randomized controlled trial investigating the influence of affective and instrumental text messages. British Journal of Health Psychology, 15, 825-840.

Spence, S. H., Donovan, C. L., March, S. et al. (2008). Online CBT in the treatment of child and adolescent anxiety disorders: Issues in the development of BRAVE-ONLINE and two case illustrations. Behavioural and Cognitive Psychotherapy, 36(Special Issue 4), 411-430.

Spence, S. H., Donovan, C. L., March, S. et al. (2011). A randomized controlled trial of online versus clinic-based CBT for adolescent anxiety. Journal of Consulting and Clinical Psychology, 79, 629-642.

Spence, S. H., Holmes, J. M., March, S. \& Lipp, O. V. (2006). The feasibility and outcome of clinic plus internet delivery of cognitive-behavior therapy for childhood anxiety. Journal of Consulting and Clinical Psychology, 74, 614-621.

Spence, S. H. \& Rapee, R. (1999). Preschool Anxiety Scale (Parent Report). Australia: University of Queensland.

Stallard, P., Richardson, T. \& Velleman, S. (2010). Clinicians' attitudes towards the use of computerized cognitive behaviour therapy (cCBT) with children and adolescents. Behavioural and Cognitive Psychotherapy, 38, 545-560.

Suler, J. (2004). The online disinhibition effect. CyberPsychology and Behavior, 7, 321-326.

van der Leeden, A. J. M., van Widenfelt, B. M., van der Leeden, R. et al. (2011). Stepped care cognitive behavioural therapy for children with anxiety disorders: a new treatment approach. Behavioural and Cognitive Psychotherapy, 39, 55-75.

Van Voorhees, B. W., Ellis, J., Stuart, S., Fogel, J. \& Ford, D. E. (2005). Pilot study of a primary care internet-based depression prevention intervention for late adolescents. Canadian Child and Adolescent Psychiatry Review = La revue canadienne de psychiatrie de l'enfant et de l'adolescent, 14(2), 40-43.

Van Voorhees, B. W., Vanderplough-Booth, K., Fogel, J. et al. (2008). Integrative internetbased depression prevention for adolescents: a randomized clinical trial in primary care for vulnerability and protective factors. Journal of Canadian Academic and Child Adolescent Psychiatry, 17(4), 184-196. 
Van Voorhees, B. W., Vanderplough-Booth, K., Fogel, J. et al. (2009). Adolescent dose and ratings of an internet-based depression prevention program: a randomized trial of primary care physician brief advice versus a motivational interview. Journal of Cognitive and Behavioural Psychotherapies, 9, 1-19.

Wiederhold, B. K. \& Wiederhold, M. D. (2005). Virtual Reality Therapy for Anxiety Disorders: Advances in Evaluation and Treatment. Washington, DC: American Psychological Association.

Williams, C., Griffin, K. W., Macaulay, A. P., West, T. L. \& Gronewold, E. (2005). Efficacy of a drug prevention CD-ROM intervention for adolescents. Substance Use \& Misuse, 40, 869-878.

Wuthrich, V. M., Rapee, R. M., Cunningham, M. J. et al. (2012). A randomized controlled trial of the Cool Teens CD-ROM computerized program for adolescent anxiety. Journal of the American Academy of Child and Adolescent Psychiatry, 51, 261-270. 